\title{
EL SANEAMIENTO DEL BARRANCO DE LA ALBUFERETA: TENTATIVAS EN EL SIGLO XX
}

\author{
Margarita Box Amorós
}

*Este trabajo ha sido realizado dentro de los planes de investigación de la Comisión Asesora de Investigación Científica y Técnica.

\section{EL MARCO FÍSICO}

Al NE de la ciudad de Alicante, incluida en su término municipal, se ubica la partida de la Albufereta, lugar que recibe esta denominación por formar parte de la misma una zona que hasta hace relativamente poco tiempo presentaba unas condiciones similares a las connotaciones que el término «albufera» lleva consigo. Se halla situada entre la Sierra de San Julián o Serra Grossa (165,5 m sobre el nivel del mar) y el montículo que constituye el llamado Monte Tossal (36,5 m sobre el nivel del mar). La zona pantanosa se instalaba en el tramo final de una barrancada que desde un sector de las alineaciones que bordean la huerta de Alicante (Loma Redonda, Lomas del Garbinet, Rincón de Santana, Las Paulinas y Monte Calvario), desagua en el Mediterráneo a través de las elevaciones de la Serra Grossa y del Monte Tossal. De todos modos, la delimitación de su cuenca vertiente es, en extremo, imprecisa, dado el grado de antropización a que se halla sometido este sector, hecho que se comprende fácilmente si se tiene en cuenta la larga tradición agrícola del mismo y la atracción que como lugar de residencia tanto definitiva como secundaria ha experimentado en los últimos años.

La justificación topográfica de este área semipantanosa reside en lo reducido de los desniveles, así, el eje fundamental de la misma presenta una pendiente que no rebasa el 1,2\% (desde la cota de 4,9 m hasta el nivel del mar), e incluso, el declive desde la isohipsa de $10 \mathrm{~m}$ no rebasa el 1,1\%. Ello explica que, normalmente, las aguas de escorrentía recogidas en su cuenca vertiente permanezcan prácticamente retenidas en el tramo final del barranco de la Albufereta, salvo en caso de lluvias muy intensas, originando, así, un área cenagosa cuyo estudio es el objeto del presente trabajo. Por otra parte, hay que tener en cuenta que esos desniveles han sido obtenidos en relación a cotas actuales, por lo que los procesos de aluvionamiento y relleno antrópico han contribuido a matizar los declives que, lógicamente, serían menos pronunciados en situaciones anteriores.

[52]

Evolución geomorfológica

El momento en el cual el área comienza a ser inundada por las aguas marinas es difícil de precisar, pero la existencia de una línea de fractura postpliocena parece ser el hecho clave. Se trata de una línea de debilidad tectónica que discurre paralela a la costa, introduciéndose tierra adentro por la Albufereta, dejando como horst el área del Cabo de las Huertas. De manera que, posiblemente, desde finales del Terciario, las aguas marinas penetraron en el sector, configurando así una especie de pequeña ría que sería aprovechada para la construcción de un puerto romano, gracias al resguardo que le proporciona el Cabo de las Huertas y que determina el cierre del golfo de Alicante por su sector septentrional.

Efectivamente, la existencia de restos arqueológicos parece demostrar que en el Monte Tossal se asentaron varias civilizaciones «hasta los tiempos más avanzados del imperio 
romano» ${ }^{1}$, pero lo más importante de todo es que, precisamente, en las excavaciones realizadas se encontraron numerosos vestigios que hacen pensar en la presencia de un antiguo puerto romano en el interior de la Albufereta ${ }^{2}$, con lo que quedaría demostrada la falta, al menos hasta ese momento, de una obstrucción y consiguiente estancamiento de las aguas, además, hay que tener en cuenta otro hecho y es que, por los restos hallados, las ciudades asentadas en el Tossal parece ser gozaron de un cierto esplendor, de manera que ese floreciente desarrollo no es compatible con una ubicación que fuera perjudicial para el bienestar de sus moradores, por ser estos terrenos pantanosos extremadamente propicios para la multiplicación de las larvas del mosquito transmisor del paludismo.

Sin embargo, la instalación aquí de una zona marismeña es un hecho que cronológicamente cabría datarlo de tiempos históricos y al que debieron de contribuir dos factores fundamentales: por un lado, una regresión del nivel marino ${ }^{3} \mathrm{y}$, en segundo lugar, la colmatación debida a aportes marinos y, sobre todo, fluviales, que coadyuvarían a la creación de una restinga de débil espesor que sería sobrepasada, únicamente, con fuertes temporales marinos o con ocasión de lluvias muy intensas y con potencia suficiente, capaces de conseguir un desagüe en el mar. Así, por ejemplo, el deán Bendicho, en su crónica sobre la ciudad de Alicante fechada en 1640 afirma que con [53]

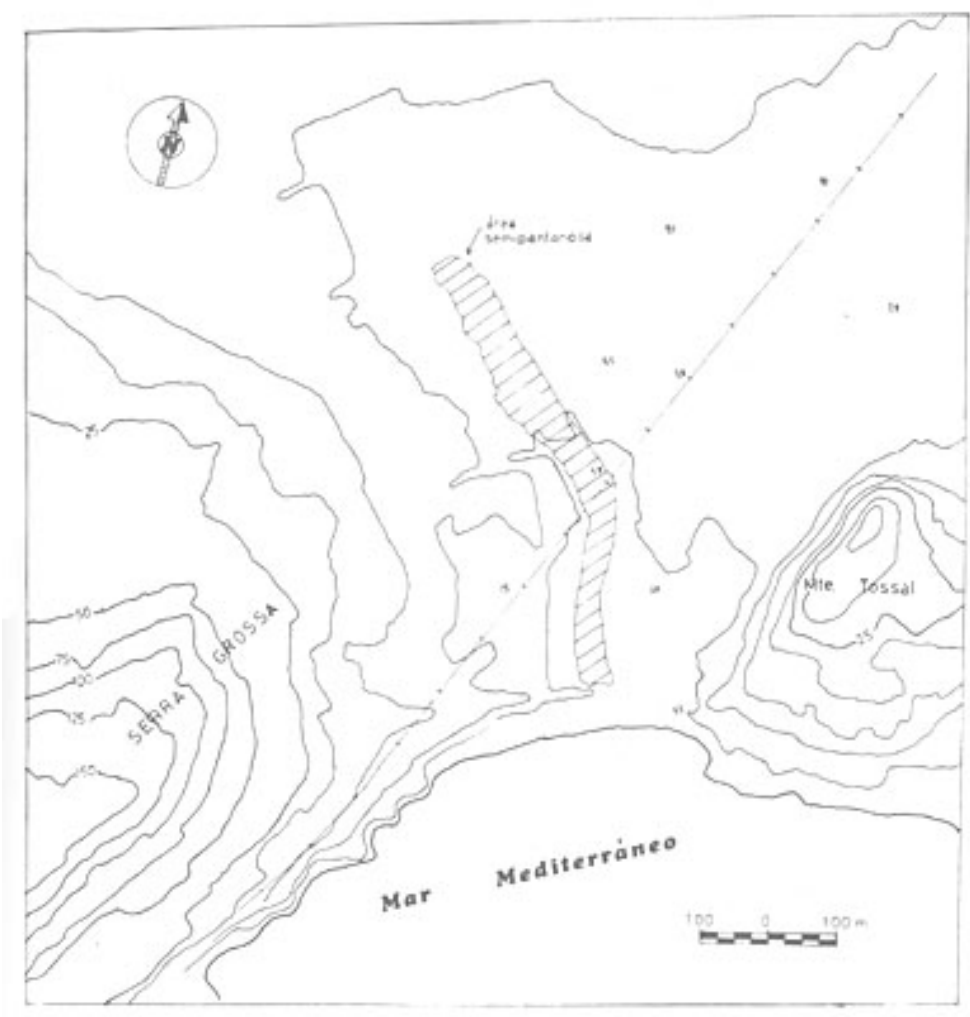

${ }^{1}$ FIGUERAS PACHECO, F.: «El antiguo puerto interior de la Albufereta de Alicante. Descubrimiento y descripción». R. A. de la Historia. Memoria de las excavaciones de Alicante. 1934 a 1936, pág. 12.

LLOBREGAT CONESA, E. A.: «Una nueva inscripción romana del Tossal de Manises y la localización del topónimo Lucentum». Rev. del I.D.E.A. N. ${ }^{\circ} 33$ (1981), pág. 24.

${ }^{2}$ FIGUERAS PACHECO, F.: Op. cit. Pág. 20.

${ }^{3}$ ROSELLÓ VERGER, V. M.: «Restos de marisma en el litoral de Xàbia (País Valenciano). Transformaciones antrópicas». Medio fisico. Desarrollo regional y Geografía. V. Coloquio de Geografia. Granada, 1977, pág. 189. 
GRÁFICO 1. Localización y extensión de la zona semipantanosa. [54]

ocasión de fuertes lluvias «Yo vi entonces que una saetía con sus velas tendidas se metió dentro de la Albufereta hasta el Cabo que es muy cerca del camino...» ${ }^{4}$.

De esta manera, y salvo ocasiones muy puntuales, la zona estudiada pasó a quedar configurada como un aguazal cuyo cordón de separación entre la zona palustre y el mar se halla integrado básicamente por materiales de aluvionamiento en superficie procedentes de los arrastres fluviales y «bajo ellos capas sucesivas de algas y arenas hasta llegar a nivel más bajo que el delmar...» ${ }^{5}$, de ahí que, habitualmente, las aguas quedasen paralizadas originando un lugar peligroso para los pobladores de las tierras inmediatas.

\section{EL SANEAMIENTO DEL BARRANCO DE LA ALBUFERETA: TENTATIVAS EN EL S. XX}

\section{Breve desarrollo histórico}

Precisamente, por sus condiciones topográficas de escaso o nulo desnivel y por el cierre determinado por la barra costera, el área reunía los requisitos ideales para convertirse en un lugar de estancamiento de aguas. Al mismo tiempo, y debido, precisamente, a las condiciones climáticas generales (temperatura media anual igual a $18^{\circ} \mathrm{C}$ ), las aguas retenidas llegaban, sobre todo en la época estival, al estado de putrefacción y, lo que es más peligroso todavía, constituían el vivero donde se multiplicaban las larvas del mosquito Anopheles, transmisor del paludismo. Ante esta situación se intentaron tomar distintos tipos de medidas, de las cuales, la más antigua recogida corresponde al Privilegio de Fernando el Católico, otorgado a la ciudad de Alicante en 1510 y en la que se expresa que:

«...ninguna persona privada / o stranya no puixa amerar lli, canem ni altre splet en l'Albufera de dita ciutat aprop de les heretats de Gaspar Bernat e d'en Antoni Merita y d'en Bernat Joan // y de moltes altres per lo gran dan queja de la infectio e males odors que donen e fanales gurts qui cullen sos fruyta en ses heretats que tenen en la dita horta sino passen lo mes de octubre.... ${ }^{6}$.

Igualmente, durante los siglos XVII y XVIII, existió una preocupación latente por poner remedio a la insalubridad de estos terrenos, así «a las iniciativas consorciadas entre el municipio y los propios interesados que parecieron viables en un primer momento, se sucedieron las puramente privadas que no consiguieron alcanzar todos los objetivos deseados, aunque contribuyeron [55] a paliar en gran medida el problema sanitario planteado» ${ }^{7}$ y es precisamente en el presente siglo cuando tiene lugar el saneamiento decisivo.

${ }^{4}$ BENDICHO: Chronica de la M. I. Noble y Leal ciu ${ }^{d}$. de Alicante manuscrito original conservado en el Archivo Municipal de Alicante. Cap. VII, pág. 26.

${ }^{5}$ FIGUERAS PACHECO, F.: Op. cit. Pág. 22.

${ }^{6}$ Archivo Municipal de Alicante (AMA) Arm. I Libro 3 Fol. 113v-114.

${ }^{7}$ ALBEROLA ROMA, A.: «Medidas contra la insalubridad en el Antiguo Régimen: Los intentos para desecar la laguna de la Albufereta (Alicante) en los siglos XVII y XVIII». Actas del VII Congreso de Historia de la Medicina. Alicante, abril, 1983 (en prensa). 


\section{Tentativas precedentes al saneamiento definitivo en el siglo $X X$}

Como ya se ha dicho anteriormente, la desecación de la Albufereta no constituye una empresa única, acordada y realizada en la actual centuria sino que representa el epílogo de una serie de tentativas que se iniciaron en siglos precedentes y que no llegaron a buen fin.

El propósito de este trabajo no es sistematizar esas diferentes iniciativas puesto que las mismas ya han sido objeto de estudio ${ }^{8}$ sino exponer el proyecto que dio fin, en la década de los años veinte del presente siglo, al estancamiento de aguas en este sector del municipio alicantino, con todas las connotaciones de insalubridad que de esta situación se derivan, hecho que ya fue puesto de manifiesto por Cavanilles en su recorrido por las tierras del antiguo Reino de Valencia a fines del s. XVIII:

«...es un depósito natural de aguas estancadas situado al nordeste de la Sierra de San Julián y principio meridional de la huerta por la banda del mar, no lejos de la antigua Lucentum... Las aguas de esta laguna, corrompiéndose en verano por falta de movimiento y por los despojos de los vegetales nativos, infectan la atmósfera, y producen tercianas muchas veces rebeldes y malignas, que desde la Condomina se extienden a los pueblos de la huerta...»».

Esta situación de insalubridad, cuyas consecuencias habían sido sufridas por la población de los alrededores, nunca había tenido un carácter oficial, pero en el Boletín Oficial de la Provincia de fecha 24 de Marzo de 1895, se insertó un Real Decreto de fecha 21 del mismo en el que se especificaba que para el cumplimiento del Art. 62 de la Ley de Aguas de 13 de Junio de 1879 vigente en ese momento, relativo a la declaración de insalubridad de lagunas y terrenos pantanosos o encharcados, los Subdelegados de Medicina y Veterinaria y los Médicos titulares, debían denunciar a la Autoridad la existencia de los mismos, al igual que podían hacerlo los particulares interesados en ello. El Gobernador Civil, una vez recibido el expediente, debía decretar su publicación en el Boletín Oficial de la provincia, expresando la declaración de insalubridad para que en el plazo de 30 días, contados a partir de la publicación del mismo, se hicieran las reclamaciones oportunas. [56]

Este Real Decreto parece ser que no tuvo ninguna consecuencia inmediata respecto a los terrenos que ahora se tratan, pues no es hasta 1925 cuando se declara oficialmente la insalubridad de los mismos. Así, en un Real Decreto del Ministerio de la Gobernación de 8 de julio de 1925 y publicado en el Boletín Oficial de la Provincia de fecha 16 del mismo, se afirma que: «...el Presidente del Colegio Médico de la Provincia de Alicante (por entonces D. Evaristo Manero Pineda), presentó la denuncia de la existencia en el partido rural de «Albufereta» de unas charcas de aguas muertas, que constituyen serios focos de infección palúdica». A raíz de esta denuncia fue decretada la instrucción del expediente para la declaración de insalubridad de los citados terrenos, llevado a cabo por los Subdelegados de Medicina y Veterinaria. Una vez que el Gobernador civil tuvo constancia del citado expediente ordenó su publicación en el Boletín Oficial de la Provincia y en la Gaceta de Madrid, al tiempo que instó al Ayuntamiento para que diera publicidad al saneamiento, con el objeto de que en virtud del punto $4^{\circ}$ del Real Decreto de 21 de Marzo de 1895, aquellos que lo estimasen efectuarán en el plazo de 30 días las reclamaciones pertinentes. Igualmente, el Ingeniero de Obras Públicas realizó un estudio en base

\footnotetext{
${ }^{8}$ Vid. ALBEROLA ROMA, A. Op. cit.

${ }^{9}$ CAVANILLES, A. J.: Observaciones sobre la historia natural, geografia, agricultura, población y frutos del Reyno de Valencia. Imprenta Real, Madrid. 1797 2. ${ }^{a}$ edic. Valencia, 1981, pág. 248.
} 
al punto $6^{\circ}$ del citado Real Decreto, presupuestando el saneamiento de unos $30.000 \mathrm{~m}^{2}$ en unas 38.000 pts. y para el que habría «que construir un canal de fábrica y elevar el resto de la rambla con presas transversales de piedra en seco, rellenando los espacios comprendidos entre ellas y efectuando plantación de consolidación...». Ese presupuesto podría quedar rebajado a 26.000 pts. «si el relleno entre presas se deja a cargo de los arrastres procedentes de sucesivas avenidas....» ${ }^{10}$.

De esta manera, el 21 de noviembre de 1925 se publicó en el Boletín Oficial de la provincia, en la Sección de Fomento, un Real Decreto por el que se anunciaba que «S.M. el Rey (q.D.G.) ha tenido a bien disponer se anuncie en la Gaceta de Madrid y en el Boletín Oficial de la Provincia, para que durante el plazo de tres meses, contados a partir de la publicación de este anuncio, se admitan proyectos y proposiciones para la ejecución de las obras de saneamiento y desecación de dichos terrenos en la Dirección General de Obras Públicas y en el Gobierno Civil de Alicante.»

Esos $30.000 \mathrm{~m}^{2}$ que habían de ser saneados formaban parte del patrimonio del Estado ${ }^{11}$, pero en el caso de que se aprobara algún proyecto, estos terrenos quedarían de propiedad del que ejecutara las obras, una vez desecados, según lo dispuesto en el Art. 65 de la Ley de Aguas de $1879^{12}$.

El estudio realizado por el Ingeniero de Obras Públicas fue revisado y analizado por los arquitectos municipales, los cuales emitieron su informe con fecha 2 de febrero de 1926 al Alcalde de la ciudad, dando cuenta del mismo y [57] de que, a su entender, una vez saneados estos terrenos podrían utilizarse como edificables, quedando, descontados los espacios libres, una extensión de $20.000 \mathrm{~m}^{2}$, el valor de los cuales iría aumentando con el tiempo, sin embargo, según los citados técnicos, en ese momento «dada la complejidad de factores que intervendrían llegado el caso para su tasación en venta se hace imposible poder fijar de antemano el valor que podrían alcanzar» ${ }^{13}$.

Este informe pasó a la Comisión de Hacienda del Ayuntamiento para que estimara si el coste del proyecto se adecuaba a las posibles consecuencias económicas que de él se derivarían ${ }^{14}$ y en sesión de 11 de febrero de 1926 se desestimó el mismo, puesto que según el Sr. Navarro de Castro, Presidente de la citada comisión, dicha obra no era conveniente para los intereses municipales ${ }^{15}$, ya que según el diario $L a$ voz de Levante «ni las disponibilidades del Ayuntamiento permitían realizar la obra, ni el valor del terreno después de saneado compensaría el gasto que aquélla exigía» ${ }^{16}$. Una vez más, había sido el obstáculo económico el que impidió llevar a efecto unas obras, en extremo, útiles para el bienestar público.

Como en otras ocasiones, fue la iniciativa privada la que también intentó resolver un problema que, a toda luces, afectaba al total de la comunidad. Sin embargo, respecto a este punto existe una cierta confusión en la documentación manejada, así mientras que en el diario La Voz de Levante de 24 de marzo de 1927 se afirma que «los propietarios de los terrenos vecinos a la

\footnotetext{
${ }^{10}$ Boletín Oficial de la Provincia de Alicante (B.O.P.) 16-julio-1925.

${ }^{11}$ B.O.P. (Alicante) 16-julio-1925. pág. 45.

${ }^{12}$ Ley de Aguas de 13 de junio de 1879 (Gaceta número 170 de 19 de junio de 1879). Edit. B.O.E. Madrid, 1975,

${ }^{13}$ AMA. Borrador de Fomento. Sec. F-3 Libro 176, fol. 71.

${ }^{14}$ AMA. Actas Capitulares 3-febrero-1926.

${ }^{15}$ AMA. Actas Capitulares 11-febrero-1926.

${ }^{16}$ La Voz de Levante 24-marzo-1928.
} 
Albufereta decidieron proceder ellos a la desecación de la misma y acogerse luego a los beneficios que en este caso les concedía el Estado», ni en los libros de Actas Capitulares ni en el resto de la información utilizada se hace referencia a este colectivo de personas sino, únicamente, a Antonio Ayús García, al que años antes le había sido denegada la aprobación del plano de alineaciones de unos terrenos de su propiedad en la partida de Albufereta ${ }^{17}$, pues según el informe del Arquitecto municipal dos eran las razones por las que creía no ser conveniente conceder dicha autorización: en primer lugar, porque se trataba de «una zona de marcada insalubridad» siendo por ello necesario llevar antes a cabo labores de saneamiento y, en segundo lugar, porque los terrenos en cuestión se ubicaban en el emplazamiento de lo que fue la antigua Lucentum y por tanto debían «tomarse las oportunas medidas preventivas para evitar que puedan estropearse los objetos de valor que allí se encuentran» ${ }^{18}$.

Este propietario presentó en el Ayuntamiento de Alicante con fecha 24 de marzo de 1927 un proyecto de desecación que pasó a la Comisión de Hacienda para su estudio. El problema de si fue un solo propietario o varios los [58] que tomaron esta iniciativa no es fácilmente comprobable puesto que el expediente presentado no se conserva en el Archivo municipal y, en consecuencia, no se puede averiguar quién fue el firmante o los firmantes del mismo; sin embargo, nos inclinamos a pensar que fue sólo Ayús García el que hizo el ofrecimiento, ya que en la totalidad de la documentación manejada figura tan sólo su nombre y, además, era uno de los principales interesados en que aquellos terrenos pudieran ser utilizados con todas las garantías de salubridad posibles, máxime si se tiene en cuenta que en las proximidades de la Albufereta estaba llevando a cabo la construcción de una gran barriada ${ }^{19}$.

El ofrecimiento realizado por Antonio Ayús se hizo mediante una instancia al Presidente de la Corporación en la que se comprometía a llevar a cabo por su cuenta el saneamiento de la Albufereta detallando en la misma una serie de condiciones. Como ya se ha dicho, la mencionada solicitud no se conserva en el Archivo municipal de Alicante pero acudiendo a la prensa local puede abrirse una luz sobre el tema. Así, el diario La Voz de Levante publicó un artículo con fecha 20 de abril de 1927 en el que se afirma lo siguiente: «Ahora es un particular especialmente interesado en ello quien se compromete a hacer la obra que todo Alicante necesita, pero pide una pequeña ayuda económica a cambio de ceder él a nuestro municipio una determinada extensión de terreno totalmente saneado y plantado de pinos y eucaliptus. La proposición no puede ser más tentadora y todo hace creer que nuestro Ayuntamiento se incline a aceptarla». Esa subvención sería de aproximadamente unas 12.000 pesetas, cantidad ésta que se cita en otro editorial del mismo periódico de fecha 24 de marzo de 1928 y en el que se atribuye, probablemente por confusión, el proyecto de desecación a un colectivo de propietarios y no únicamente a Antonio Ayús García.

Posiblemente éstas fueran las condiciones que se especificarían en el ofrecimiento de este propietario cuya proposición pasó a la Comisión de Hacienda para su estudio ${ }^{20}$; sin embargo, y aunque todo hacía pensar que el proyecto fuese aprobado, éste quedó en un «impasse» hasta tanto una comisión integrada por los concejales Srta. García Trejo y los Sres. Más Magro, Yborra, Llopis y Vañó, junto con el ingeniero municipal, visitaran el lugar y propusieran lo que

\footnotetext{
${ }^{17}$ AMA. Actas Capitulares 27-mayo-1925.

${ }^{18}$ AMA. Borrador de Fomento. Sec. F-3. Libro 174.

${ }^{19}$ AMA. Borrador de Fomento. Sec. F-3 Libro 176.

${ }^{20}$ AMA. Actas Capitulares. 23-marzo-1927.
} 
estimasen conveniente ${ }^{21}$. Esta detención momentánea del proyecto obedeció, según La Voz de Levante, a la publicación el día 20 de abril de 1927 de un artículo en dicho periódico que hizo reflexionar a la Srta. García Trejo sobre la posibilidad de que fuera el Ayuntamiento el que sanease los terrenos obteniendo así un beneficio mayor que si era llevado a cabo por los «particulares». Según dicho artículo, si la citada proposición cubría todas las necesidades y además era más barata que la que anteriormente había desechado la corporación municipal (proyecto del ingeniero de Obras Públicas [59] de 1925) «creemos que es preferible que la Albufereta sea saneada por nuestro Ayuntamiento que al entrar en posesión de unos terrenos podría con muy poco convertirlos en un espléndido jardín» ${ }^{22}$. Igualmente, en dicho escrito se consideraba que, en caso de que la obra fuese demasiado costosa para el municipio, éste debía solicitar del Estado la ayuda necesaria «para que sea saneado un terreno que el propio Estado declara peligroso para nuestra salud».

Que fueran o no éstos los motivos reales por los que el proyecto formulado por la iniciativa privada no se llevara a cabo, es algo que no podemos confirmar, pero lo verdaderamente cierto es que las obras de saneamiento del barranco de la Albufereta fueron definitivamente realizadas por el Ayuntamiento de Alicante con fondos de las arcas municipales.

\section{El proyecto del ingeniero Sebastián Canales}

De esta manera, el entonces Alcalde de la ciudad Sr. Suárez Llanos ordenó al ingeniero municipal D. Sebastián Canales que formulase el proyecto de saneamiento del barranco de la Albufereta $^{23}$. El informe emitido por el mismo tampoco se conserva en el Archivo Municipal de Alicante ${ }^{24} \mathrm{y}$ es, únicamente, la prensa del momento la que ofrece alguna característica técnica del mismo, así, en La Voz de Levante de 8 de junio de 1927 se expone que: "Se trata de un terreno pantanoso cuyo nivel es superior al del Mediterráneo. La desecación se hará fácilmente por medio de zanjas o tubos con cierta pendiente que reciban y conduzcan el agua al mar. Ya está todo dispuesto para la semana próxima levantar el plano detallado del terreno con curvas de nivel y cuantos datos sean imprescindibles para formular el proyecto definitivo en el que se detallen la dirección en que deben colocarse los drenes y colectores».

Casi un año después de iniciarse los trámites que conducirían a la desecación definitiva de la Albufereta, se aprobó en sesión capitular de 28 de marzo de 1928 el proyecto del ingeniero Canales, cuyo total importe ascendía, según el presupuesto realizado por el mismo, a 5.567,23 pesetas, «autorizándose a la Alcaldía para ejecutarlo por contratación directa, en vista de que el contrato, por su cuantía, se halla comprendido en el $n^{\circ} 1$ del artículo 164 del Estatuto municipal», dicho informe fue remitido al Gobierno civil con la misma fecha.

De esta manera, en el Boletín Oficial de la Provincia de fecha 31 de marzo de 1928, se publicó un edicto suscrito por el Alcalde Suárez Llanos para contratar la ejecución de las obras de desecación y saneamiento del barranco [60] de la Albufereta, admitiéndose «cuantas proposiciones se le formulen por escrito y en pliego cerrado hasta el día dos del próximo mes

${ }^{21}$ AMA. Actas Capitulares 21-abril-1927.

${ }^{22}$ La Voz de Levante 20-abril-1927.

${ }^{23}$ La Voz de Levante 4-mayo-1927.

${ }^{24}$ Este proyecto ha sido buscado en el organismo antes mencionado, además de en el Archivo del Gobierno Civil de Alicante, Delegación del Ministerio de Obras Públicas, Biblioteca de la Caja de Ahorros de Alicante y Murcia, donde se conservan los fondos documentales del ingeniero Canales, y en la Diputación Provincial, sin ningún resultado positivo. 
de abril a las doce horas». Las ofertas presentadas, previa fianza de 250 pesetas, para garantizar el cumplimiento de las obras, debían incluir la cuantía de los trabajos a realizar con arreglo al proyecto del técnico municipal y el plazo máximo de terminación de las obras.

Sin embargo, nadie presentó ninguna proposición al tema, de manera que una vez agotado el plazo de admisión previsto la Alcaldía, en sesión capitular de 11 de abril de 1928, acordó la contratación directa de las mismas con el maestro de obras D. Agustín Pantoja Graciá $^{25}$, a quien con fecha 12 del mismo mes le fue remitido oficio encomendándole la ejecución de las obras de saneamiento. Dichas obras, según consta en el Libro de Actas Capitulares $^{26}$, quedarían finalizadas el día 15 de mayo de 1928, es decir, prácticamente un mes después de iniciadas y se ajustarían al proyecto y presupuesto formulado por el ingeniero Sebastián Canales. Igualmente para llevar a cabo los trabajos necesarios se envió desde la Alcaldía un oficio de fecha 12 de abril del mismo año al Comandante Militar de Marina para que tramitase las órdenes oportunas para que las tuerzas de carabineros no ofrecieran oposición a las obras que iban a realizarse.

En cuanto a quién sufragó los gastos de saneamiento nada aparece registrado a este respecto en las sesiones concejiles y una vez más la prensa local es la que permite ampliar el tema. Así en el diario La Voz de Levante de 4 de mayo de 1927 se dice que según las propias palabras del Sr. Canales «el coste de esa obra será atendido proporcionalmente por el Ayuntamiento y por los propietarios interesados...», si bien no se especifica en qué proporción contribuiría cada una de dichas partes. De la misma manera, el diario El Luchador, de tendencias republicanas, en su edición de 28 de marzo de 1928, al dar cuenta de los asuntos que se tratarían en la sesión capitular a celebrar en ese mismo día dice: «Nuestros ediles acuerdan imponer la contribución del 30 por cien a los propietarios colindantes a estas obras». Esta afirmación no puede ser confirmada puesto que en el Libro de Actas no aparece ninguna referencia a este tema, e incluso, al ser revisados los libros de ingresos del Ayuntamiento no se registra ningún montante por este concepto.

Lo único realmente comprobable es que D. Agustín Pantoja Graciá realizó las obras de saneamiento y que el Ayuntamiento expidió a su favor cinco mandamientos de pago con fechas 5 de mayo, 26 de mayo, 16 de junio, 31 de agosto y 22 de diciembre de 1928 por un importe total de 5.023,54 pesetas por la ejecución de las mismas y en las que se invirtieron los siguientes materiales $^{27}:[61]$

366,00 metros lineales de emisarios y dren principal................................1.899,54 Ptas.

90,00 metros lineales de emisario del tipo A 423,00 Ptas.

6,50 metros cúbicos de hormigón en sacos en la desembocadura. 325,00 Ptas.

41,00 metros lineales de tubería de barro 246,00 Ptas.

25,00 metros de tubería de barro sentada sobre hormigón 225,00 Ptas. 40,00 metros cúbicos de escollera 280,00 Ptas. 650,00 metros cúbicos de terraplén $1.625,00$ Ptas.

\section{TOTAL 5.023,54 Ptas.}

\footnotetext{
${ }^{25}$ Agustín Pantoja Graciá fue uno de los maestros de obras que frecuentemente realizó obras de urbanización en la ciudad, encomendadas por el Ayuntamiento de la misma.

${ }^{26}$ AMA. Actas Capitulares 11-abril-1928.

${ }^{27}$ AMA. Carpeta de Mandamientos de pago correspondientes al año 1928.
} 
En definitiva, la desecación del barranco de la Albufereta no sólo no sobrepasó el presupuesto originario (5.567,24 Ptas.) sino que ni tan siquiera lo alcanzó, y en ella el elemento principal fue la construcción de un tubo de drenaje a lo largo de toda la zona que ocupaba el área encharcada con una profundidad suficiente para absorber las aguas que se infiltraban en el terreno y que a través de dicho emisario fueron conducidas al mar ${ }^{28}$.

Las obras debieron estar concluidas a comienzos del mes de Junio de 1928, puesto que en un artículo de La Voz de Levante de fecha 29 de mayo del citado año y cuyo título es «La Albufereta en seco» se afirma que «...Están ultimándose los últimos detalles de la obra de desecación de la Albufereta... y que ha sido tan eficaz que ha hecho desaparecer totalmente aquella charca...».

La desecación de esta zona pantanosa constituía, como ya se ha dicho, un capítulo importante para el saneamiento de la ciudad y su término municipal, y la mayoría de los intentos de reducir ese foco palúdico que casi todos los veranos generaba nubes de mosquitos muy peligrosos para la salud pública había chocado con el problema económico para poder ser llevado a cabo. La prensa local y, concretamente, el diario La Voz de Levante, el de mayor tirada en la década de los veinte en la ciudad, hizo un extraordinario hincapié para que las autoridades competentes llevaran a cabo el saneamiento con la publicación prácticamente diaria de artículos sobre el tema, si bien se sobrevaloró el resultado que los trabajos pudieran tener, pues resulta anecdótico que para dicho periódico los terrenos, una vez desecados, constituirían «un espléndido jardín que sirviese de esparcimiento a los alicantinos y que nada tendría que envidiar al Retiro de Madrid, los Viveros de Valencia, el Parque de Barcelona, el de María Luisa de Sevilla... a los que superaría con creces porque a la habilidad de nuestro jardinero municipal se uniría la bondad del clima y el paisaje imponderable que desde «La Albufereta» se domina» ${ }^{29}$.

Ciertamente, los resultados fueron muy distintos, pero de todas maneras, [62] las obras de drenaje surtieron un efecto positivo y la Albufereta a partir de entonces se convirtió en un lugar muy frecuentado por los alicantinos, sobre todo en la época estival, con la instalación de muchas casetas para baños y la construcción de un merendero en el que su propietario, D. Pascual Villacieros, invirtió 300.000 pesetas, suma realmente importante para el momento ${ }^{30}$. Probablemente, la situación de los terrenos saneados y el valor de los mismos hubiera adquirido mayores proporciones en un plazo de tiempo más breve al que tuvo, si las autoridades municipales se hubiesen preocupado por el mantenimiento de las obras de infraestructura realizadas para el saneamiento, puesto que con el paso del tiempo parece ser que los terrenos volvieron a adquirir un carácter semipantanoso, ello se desprende de la denuncia que hizo el Diario de Alicante con fecha 2 de noviembre de 1931 y en el que se insertó el siguiente párrafo: «Seguramente por falta de una monda frecuente y metódica han perdido su eficacia los trabajos de desagüe que se realizaron y «La Albufereta» vuelve a ser un lugar pantanoso, insalubre, por tanto, y peligroso para la colonia que a su alrededor se ha formado desde su saneamiento.»

Probablemente se llevaron a cabo las labores pertinentes devolviendo la salubridad a los terrenos puesto que, desde esta época, no se ha vuelto a tomar ningún tipo de medidas de carácter extraordinario a este respecto.

La situación actual, desde el punto de vista físico, es la de un área que sigue manteniendo unas condiciones de humedad importantes, prueba de ello es la abundancia de cañaverales, sobre todo, hasta el límite de la vía férrea (Alicante-Denia), sin embargo, el tramo final hasta la desembocadura está siendo explotado por el Ayuntamiento de Alicante como zona de

\footnotetext{
${ }^{28}$ La Voz de Levante 29-mayo-1928.

${ }^{29}$ La Voz de Levante 20-abril-1927.

${ }^{30}$ La Voz de Levante 26-mayo-1928.
} 
aparcamiento, dada la gran afluencia turística que la playa de la Albufereta mantiene. Esta utilización tiene su raíz en la concesión otorgada al mismo por la 3. ${ }^{a}$ División Hidrológica Forestal en 1965, previo pago de 150.000 pesetas, en concepto de valor del terreno a ocupar (1,50 ha), haciendo mención expresa en el punto $5^{\circ}$ de dicho otorgamiento que «La ocupación se concede para aparcamiento de vehículos no pudiendo ser destinado a otro fin» siendo, según el punto $6^{\circ}$, «el plazo por el que se concede la ocupación de 99 años como máximo» ${ }^{31}$.

En definitiva, una situación que, con mucho, se aleja de esas perspectivas de futuro tan prometedoras que, en su día, se auguraron para estos terrenos.

${ }^{31}$ AMA. Actas Capitulares 30-junio-1965. 